\title{
Editorial
}

\section{Ultrasonografía y Diagnóstico Prenatal}

\author{
Pilar Diaz Corvillon ${ }^{1,2}$, Enrique Oyarzun Ebensperger ${ }^{3}$
}

\footnotetext{
${ }^{1}$ Residente de Medicina Materno Fetal. Pontificia Universidad Católica de Chile.

${ }^{2}$ Servicio de Obstetricia y Ginecología, Clínica Dávila.

${ }^{3}$ Departamento de Obstetricia y Ginecología. Universidad de los Andes y Clínica Universidad de los Andes.
}

En este número de nuestra revista, dos artículos tienen relación con el diagnóstico prenatal de malformaciones congénitas y alteraciones cromosómicas. El primero refiere la experiencia del Hospital Dr. Sótero del Río, con 404 pacientes evaluadas entre 2010 y 2019 por sospecha de malformaciones congénitas (MC) o marcadores de aneuploidías, a una EG promedio de 29 semanas. En algo más de la mitad se realizó estudio genético, encontrando resultado anormal en el $40 \%$ de los casos. No sabemos cuántos recién nacidos hubo con malformaciones no diagnosticadas ya que el trabajo sólo analiza las pacientes evaluadas por sospecha ultrasonográfica.

El segundo trabajo proviene del Hospital Clínico de la Universidad de Chile y analiza la frecuencia de las 3 alteraciones cromosómicas consideradas letales en la ley de interrupción voluntaria del embarazo (trisomías 9,13 y 18), en los estudios citogenéticos prenatales (en líquido amniótico o sangre fetal), realizados entre 2000 y 2017. Hubo 2305 muestras, de las cuales 19\% correspondieron a dichas aneuploidías. La mayor parte de las muestras fueron en líquido amniótico (93.5\%), y un $43 \%$ del total de exámenes realizados resultaron anormales.

Es interesante que el porcentaje de muestras anormales es similar en ambos trabajos, alrededor de $40 \%$. Como los autores del primer trabajo mencionan, también llama la atención el hecho de que la edad gestacional promedio del examen realizado fue 29 semanas, lo que es una edad avanzada para los esfuerzos que se han hecho en el diagnóstico precoz de aneuploidías, con el fin de practicar la terminación del embarazo, o aborto, precozmente.

Ambos trabajos reconocen en sus referencias el aporte del pediatra Julio Nazer que es probablemente quien más publicó en Chile respecto de este tema, permitiendo conocer mejor la epidemiologia nacional al respecto.

En relación a malformaciones congénitas, si se examina nuestra Revista Chilena en los últimos 200 25 años, existen muchos casos clínicos reportados, pero también experiencias mayores como las de González y colaboradores en el Sótero del Río $(1999)^{1}$, las del CERPO (2004) $)^{2}$, las numerosas contribuciones de Viñals y Giuliano en Concepción (2002 y otras) $)^{3,4}$, las de Rubén González en el SSMS $(2005)^{5}$, por ejemplo. La sensibilidad diagnóstica del ultrasonido (US) para MC en las series nacionales muestra resultados similares a las series extranjeras, alrededor del $50 \%$.

Los dos estudios clásicos más importantes para establecer la incidencia de anomalías congénitas mayores y menores fueron el de Marden y cols. $(1964)^{6}$ y el de Chung y cols. (1987)..$^{7}$ En ambos estudios el porcentaje total sumando anomalías congénitas mayores y menores se acerca al $16 \%$ de los RN examinados; para el primer estudio, $2 \%$ de malformaciones mayores y $14 \%$ con alguna malformación menor en 4412 recién nacidos ( $\mathrm{RN}$ ); y para el segundo, $6 \%$ malformaciones mayores, y $15 \%$ de anomalías totales en 52332 RN. En Chile, el estudio más importante es el de Nazer $(2011)^{8}$ que incluye varios países latinoamericanos analizando 2.409.207 RN, con un $2.7 \%$ de malformaciones mayores en general, y $3.1 \%$ en Chile (3.9\% en estudio posterior del 2014) ${ }^{9}$.

En la medida que los países se desarrollan, prematurez y malformaciones congénitas son las dos causas más importantes de morbimortalidad perinatal.

La discusión hasta avanzados los años 80 respecto de ecografía y embarazo era en relación a si toda paciente embarazada debía tener ecografía, y el $\mathrm{NIH}$ (EE.UU) en la época aconsejaba examen selectivo sólo por un número de indicaciones 
específicas. Los estudios randomizados al respecto, comparando ecografía de rutina versus selectiva, no han mostrado reducción de la mortalidad perinatal ${ }^{10}$.

En la actualidad el US forma parte rutinaria del control prenatal, y en la última guía nacional, correspondiente al año 2015, ${ }^{11}$ donde muchos médicos del país trabajamos, sugerimos, como otros centros del mundo, realizar 3 exámenes durante el embarazo, cada uno de ellos con fines específicos (11 a 14, 22 a 24 y 30 a 34 semanas).

Hoy muchas pacientes acuden a más exámenes ultrasonográficos de los indicados, reemplazando incluso controles prenatales formales. Aún más, algunos médicos utilizan esta herramienta diagnóstica en su consulta. $\mathrm{Y}$ si bien debemos reconocer que las imágenes hoy ofrecidas por la tecnología son atractivas, el hacer bien las cosas exige que los centros académicos y con programas de posgrado en la especialidad respondan preguntas que antes no existían:

¿Son los objetivos del control prenatal los mismos del pasado? Si la detección de MC 0 de cromosomopatías es un objetivo, ¿cómo lo hacemos? ¿Realizamos ecografía entre las 11 y 14 semanas, y además diagnóstico prenatal no invasivo en sangre materna? ¿En toda la población? ¿A qué edad gestacional?

Si se trata de hacer un aborto sería importante un diagnóstico lo más precoz posible, porque vaciar el útero puede ser más sencillo que a edades gestacionales mayores, y socialmente los cercanos a la paciente quizás no se enteren del embarazo. Si no se trata de hacer un aborto, el diagnóstico precoz no parece tan importante. En el futuro el diagnóstico prenatal en sangre materna será de muy bajo costo, y se podría plantear realizarlo a toda la población con un examen de US a cierta edad gestacional de acuerdo a los objetivos buscados. La evidencia hoy disponible muestra que el examen materno no basta, y que por lo tanto no reemplaza al examen de US ${ }^{12}$.

Si el diagnóstico prenatal de las MC es un objetivo, es evidente que debemos incluir una adecuada evaluación cardíaca, dado que esas malformaciones están entre las más frecuentes al nacer ${ }^{13}$.

$\mathrm{Y}$, finalmente, todo aquel que haga un diagnóstico prenatal de alguna anormalidad, asume una responsabilidad que obliga a dedicarle tiempo suficiente a esos padres, acompañarlos, apoyarlos psicológica y emocionalmente, e informarlos adecuadamente, con otros especialistas, acerca de la certeza diagnóstica, pronóstico, y posibles intervenciones fetales o neonatales. Desde el punto de vista de políticas públicas, debe además alcanzarse un equilibrio entre los costos económicos de un programa y lo que es mejor para los miembros de la sociedad.

En la actualidad existe preocupación por la medición de calidad en todas las especialidades médicas, y existen indicadores aceptados, de modo que los Departamentos y servicios clínicos deberán, tarde o temprano, evaluar sus porcentajes de inducción de trabajo de parto, de operación cesárea, de necesidad de transfusiones sanguíneas, y también, por cierto, el diagnóstico prenatal de malformaciones congénitas. Aún más, estas cifras deberán ser conocidas y de dominio público, por centro o establecimiento, y también por individuo, de modo que cada paciente decida donde se controlará no sólo de acuerdo a los costos, sino también de acuerdo a los resultados mostrados.

\section{REFERENCIAS}

1. González R, Cartens M, Gómez R, Medina L, Gutiérrez J, Arriagada $\mathrm{P}$, . Anomalías congénitas en población de bajo riesgo: screening con ultrasonido prenatal en un sistema público de salud. Rev Chil Obstet Ginecol 1999; 64: 247-55.

2. Rodríguez A JG, Enríquez G G, Hering A E, et al. Centro de referencia perinatal oriente (CERPO): evaluación de la experiencia del primer año. Revista chilena de obstetricia y ginecología 2004; 69: 107-11.

3. Viñals L. F, Giuliano B. A. Cardiopatias congenitas: incidencia antenatal. Revista chilena de obstetricia y ginecología 2002; 67: 203-6.

4. Viñals L. F, Giuliano B. A. Cardiopatias congenitas: incidencia postnatal (II). Revista chilena de obstetricia y ginecología 2002; 67: 207-10.

5. González G. R, Dezerega P. V, Vásquez M. R. Contribución de la ecografía rutinaria en el período 22 a 26 semanas al diagnóstico de anomalías congénitas: experiencia de 2 años, en 1162 ecografías. Revista chilena de obstetricia y ginecología 2005; 70: 289-95.

6. Marden P, Smith D, McDonald M. Congenital anomalies in the newborninfant, including minor variations: A study of 4,412 babies by surface examination for anomalies and buccal smear for sex chromatin. J Pediatr 1964; 64: 357-71.

7. Chung CS, Myrianthopoulos NC, Opitz JM, Reynolds JF. Congenital anomalies: Mortality and 
morbidity, burden and classification. Am J Med Genet 1987; 27: 505-23.

8. Nazer $\mathrm{H}$ J, Cifuentes $\mathrm{O}$ L. Malformaciones congénitas en Chile y Latino América: Una visión epidemiológica del ECLAMC del período 19952008. Revista médica de Chile 2011; 139: 72-8.

9. Nazer $\mathrm{H}$ J, Cifuentes $O$ L. Prevalencia al nacimiento de malformaciones congénitas en las maternidades chilenas participantes en el ECLAMC en el período 2001-2010. Revista médica de Chile 2014; 142: 1150-6.

10. Bricker L, Medley N, Pratt JJ. Routine ultrasound in late pregnancy (after 24 weeks' gestation). Cochrane Database Syst Rev 2015; : CD001451.

11. MINSAL. Guia perinatal. 2015 https://www.minsal.cl/sites/default/files/files/GUI A\%20PERINATAL_2015_\%20PARA\%20PUBLI CAR.pdf.

12. Miranda J, Miño FP y, Borobio V, et al. Should cell-free DNA testing be used in pregnancy with increased fetal nuchal translucency? Ultrasound in Obstetrics \& Gynecology 2020; 55: 645-51.

13. Yagel S, Cohen SM, Achiron R. Examination of the fetal heart by five short-axis views: a proposed screening method for comprehensive cardiac evaluation. Ultrasound Obstet Gynecol 2001; 17: 367-9. 